Estudios Públicos I6I (202I), 2I3-2I8

DOI: https://doi.org/I0.38178/07/83089/3010201804

Res e ña

Benjamín Ugalde, Felipe Schwember y Valentina Verbal (eds.). El octubre chileno. Reflexiones sobre democracia y libertad. Santiago: Ediciones Democracia y Libertad, 2020. US\$19, I0 (ISBN: 9789560949400$), 278$ pp.

\title{
Julieta Suárez-Cao
}

Pontificia Universidad Católica de Chile, Chile

I estallido social del 18 de octubre de 2019 traerá, sin lugar a dudas, tar comprender no solo qué pasó, sino también las condiciones que llevaron a que ocurriesen las protestas, las manifestaciones masivas y la ola de violencia que las acompañó. En este marco se inscriben los ensayos del libro El octubre chileno. Reflexiones sobre democracia y libertad, editado por Benjamín Ugalde, Felipe Schwember y Valentina Verbal, primer volumen de la recientemente creada Ediciones Democracia y Libertad.

Desde una perspectiva muy amplia de ámbitos de estudio, como el derecho, la filosofía, la historia, la economía, la ciencia política y la sociología, los autores de El octubre chileno - académicos, intelectuales y personalidades reconocidas - presentan las primeras reacciones que matizan o directamente disienten de las interpretaciones dominantes respecto del estallido social.

En este sentido, los ensayos pueden leerse como un compendio de argumentos e interpretaciones con diferentes grados de plausibilidad y de hipótesis a evaluarse en futuras investigaciones empíricas, que son producto de una cercanía con el evento analizado. Esta proximidad entre los escritos del volumen y el evento analizado, que en su amplia mayoría fueron producidos con anterioridad a la pandemia del coronavirus en Chile, le dan al libro una característica paradójicamente atemporal y lo vuelven material de consulta obligada para quienes hoy y en el futuro

Julieta SuÁrez-CaO es Doctora y Magíster en Ciencia Política, Universidad de Northwestern, Estados Unidos, y Licenciada en Ciencia Política, Universidad de Buenos Aires, Argentina. Profesora asociada del Instituto de Ciencia Política, Pontificia Universidad Católica de Chile. Dirección: Av. Vicuña Mackenna 4860, Macul, Santiago, Chile, CP 781000. Email: julieta.suarez@uc.cl. 
estudien las protestas de octubre 2019 y quieran conocer las primeras reacciones e interpretaciones de figuras de la derecha y la centro-derecha liberal en Chile.

El libro cuenta con once capítulos divididos en cinco secciones. Comienza con los antecedentes históricos (los capítulos de Alfredo JocelynHolt y Valentina Verbal), y continúa con la lucha por la interpretación (los capítulos de Benjamín Ugalde y Francisca Dussaillant), la violencia (los capítulos de Felipe Schwember y Luis Placencia), la protesta (los capítulos de José de la Cruz Garrido y José Miguel Aldunate) y, por último, termina con una discusión respecto de la relación entre la crisis y las instituciones (los capítulos de Natalia González, Daniel Brieba y Cristóbal Bellolio, y Carlos Newland y Emilio Ocampo). Estas secciones cumplen con la función de proveer un cierto orden a las reflexiones, a pesar de que, por supuesto, hay temas que se abordan en varios de los textos.

Debido a la gran variedad de autores/as y planteamientos, la presente reseña se focaliza en temas transversales, haciendo mención ocasional a algunos de los capítulos. Por restricciones de espacio no se realiza un resumen de cada capítulo, sino que se prioriza un comentario analítico general, con ciertos aterrizajes en los argumentos de algunos de los autores. Como todo recorte, este es arbitrario y responde tanto a una lógica de familiaridad de los temas y las disciplinas como a cuestiones de interés personal. Se invita al público interesado a acercarse al libro para poder apreciarlo en toda su complejidad, la cual es imposible relevar en estas pocas páginas.

El octubre chileno incluye planteos que desafían a las interpretaciones más simplistas, únicamente focalizadas en el modelo económico de mercado como la causa profunda del estallido. Así, se avanza en otras cuestiones históricas, legales, filosóficas y sociales que son postuladas como condiciones relevantes, con menor o mayor grado de éxito en la argumentación, para entender el estallido social. El objetivo de plantear relatos alternativos desde el liberalismo para entender los acontecimientos de octubre 2019, en particular focalizados en el aspecto de la violencia, contribuye a abrir el abanico de investigaciones futuras que se dedicarán, seguramente desde las ciencias más empíricas, a encontrar evidencia que permita evaluar cuán válidas son las inferencias causales alternativas, y desde el conocimiento teórico se dispondrán a argumentar convincentemente por una interpretación por sobre las otras. 
La complejización del entendimiento de las causas socioeconómicas del estallido es una de las contribuciones más importantes del libro. Por esta complejización se entiende desde el rechazo directo hasta la incorporación de matices interesantes sobre las demandas al Ilamado modelo neoliberal. El capítulo de Daniel Brieba y Cristóbal Bellolio, por ejemplo, propone que es un error interpretar las demandas ciudadanas como un rechazo profundo al liberalismo in toto, sino que sería un cierto tipo de liberalismo el que estaría en cuestionamiento y sería posible, entonces, canalizar algunas de estas reivindicaciones dentro de, sugieren los autores, un liberalismo igualitario.

Sin embargo, no todos los autores del libro acordarían con esta visión. Las demandas del estallido social, al ser un conjunto de eventos de protestas y manifestaciones inorgánicas, están abiertas a decodificación. Respecto de esta última, el libro critica e interpela a aquellas interpretaciones colectivistas de intelectuales de izquierda, pero también de su propio sector. En su texto, Benjamín Ugalde extiende esta decodificación colectivista hasta el propio presidente de la República, Sebastián Piñera, quien habría renunciado no solo a su programa de gobierno sino también a la defensa del liberalismo económico y social frente a las demandas que se decodifican como 'socialismo antimercado'.

En la misma línea, el capítulo de Valentina Verbal encuentra las raíces de esta claudicación del gobierno en el desconocimiento de la derecha de su propia historia y en el hecho de haber aceptado que la desigualdad socioeconómica, y no la pobreza, es el principal problema de la sociedad chilena. Esto permite que la decodificación predominante de las protestas, o de la violencia, en palabras de Verbal, haya sido en torno a la desigualdad, en vez de salir a luchar por una interpretación alternativa más afín al canon y a la historia de la derecha. Esto genera tensiones con otras visiones sobre el pluralismo al interior de la derecha chilena, que subrayan la existencia de sensibilidades para entender la diversidad en el sector y que se encuentran empíricamente respaldadas en un tercio de la dirigencia de Chile Vamos; se trata de una sensibilidad solidaria que no responde directamente al canon expuesto por Verbal. ${ }^{1}$ Esta derecha solidaria aparece en varios capítulos del libro, encarnada en la obra de Hugo Herrera y Daniel Mansuy, y es descrita como antagonista

\footnotetext{
${ }^{1}$ Véase, por ejemplo, el capítulo de Alenda, Le Foulon y Suárez-Cao (2020).
} 
y promotora de visiones comunitarias, totalizantes y colectivistas, al mismo nivel que otros autores de izquierda como Alberto Mayol y Fernando Atria.

Además del tema central del modelo económico, el énfasis en la violencia es otro eje que recorre los análisis del libro de manera potente. Si bien es cierto que se mencionan las manifestaciones y protestas pacíficas, estas no reciben el mismo nivel de análisis que sus contrapartes violentas. El capítulo de Felipe Schwember propone entender la violencia destructiva y persistente de octubre 2019, a partir de la representación de injusticias históricas que exceden el famoso adagio'no son treinta pesos, son treinta años', y que pueden remontarse hasta el pasado colonial. Así, en la opinión del autor, se impone la necesidad de un nuevo trato, de un reconocimiento de las vulneraciones percibidas o reales de una parte de la población nacional y del requerimiento de reformas al modelo, más que de un reemplazo del mismo.

Es probablemente en las discusiones sobre el estallido y el liberalismo donde El octubre chileno logra proporcionar sus mejores argumentos y matices. La discusión sobre la violencia también otorga momentos interesantes de reflexión, aunque se extraña la misma atención tanto sobre las manifestaciones pacíficas como sobre la represión y la violación de los derechos humanos, que se mencionan siempre tangencialmente y cuando se analizan expresamente, en el capítulo de José Miguel Aldunate, por ejemplo, se lo hace en profundidad pero de manera tal que queda la impresión de que se termina exculpando tácitamente a los principales responsables políticos de los abusos de las fuerzas del orden.

Para contextualizar este desequilibrio, considero relevante traer a colación que los capítulos del libro fueron redactados con mucha cercanía al estallido social, y la presente reseña se escribe habiendo transcurrido un año desde entonces y estando en conocimiento de la disminución de la violencia a partir de la pandemia, del comienzo del proceso constituyente con el triunfo aplastante del apruebo y de la convención constitucional como órgano a redactar la nueva constitución, así como de la inexistencia de evidencia en cuanto a alguna injerencia extranjera en las protestas. Las reflexiones del libro son eso mismo: reflexiones cercanas al acontecimiento que, como tales, cuentan con información preliminar que es a su vez procesada a través de la propia percepción y perspectiva ideológica de cada autor o autora de los capítulos. 
Las disquisiciones sobre el modelo y el liberalismo representan un aporte fundamental del libro a la discusión nacional, y son producto de un punto fuerte de la obra colectiva: la diversidad de disciplinas desde las cuales se piensa el estallido social. La diversidad es así un plus que lamentablemente se pierde en otros aspectos. Por ejemplo, llama la atención la poca presencia de uno de los protagonistas principales del estallido social como lo es el movimiento feminista. Los pocos capítulos que hacen referencia, por ejemplo, al fenómeno de Lastesis, que es un ejemplo paradigmático de protesta no violenta y que nació del octubre chileno y se proyectó hacia el mundo, no terminan de encontrar el tono. O se refieren a ellas de manera sarcástica o realizan críticas que denotan una falta de conocimiento de los sesgos de género en las instituciones políticas. En este sentido, el libro se habría beneficiado con una mayor variedad de género entre sus autores.

Gracias a la diversidad disciplinar, el mayor activo de El octubre chileno es la apertura a pensar fuera de la caja, a imaginar nuevas interpretaciones y explicaciones que no necesariamente repliquen las que vienen predominando. En esta clave, el capítulo de Natalia González argumenta que la reforma electoral que amplió el espectro de representación, terminó trasladando la lógica de 'la calle' al Congreso y, con esta, el quiebre de los acuerdos parlamentarios y el crecimiento de la polarización, en un proceso en cierta medida paralelo al estallido social de octubre. Siguiendo a Samuel Huntington, se podría inferir de este capítulo que la autora cree que las instituciones del binominal lograban canalizar las demandas sociales $y$, que tras la reforma electoral, estas nuevas instituciones se vieron desbordadas hacia la calle y las protestas.

Para realizar un argumento convincente en este sentido se necesita sopesar hipótesis alternativas. De lo contrario, es fácil confundir síntoma con causa. Argüir que una mayor representatividad es lo que lleva al estallido social implica soslayar la orfandad de representación de la mayor parte de la sociedad chilena, lo cual ha venido siendo señalado por las ciencias sociales en las últimas décadas como efecto del mismo sistema binominal y de estos acuerdos que se parecen añorar. La hipótesis alternativa, que dejo a consideración de quienes lean la presente reseña, apuntaría a la relación opuesta e indicaría que la crisis aguda de gobernabilidad que venimos viviendo desde octubre de 2019 es producto directo de la crisis crónica de representación que la reforma electoral no logró subsanar. 
Finalmente, citando a una de las autoras del libro, Francisca Dussaillant, destacaría que "una buena práctica en tiempos de crisis es desconfiar de las narrativas simples" (95). En este sentido, el libro aporta nuevas interpretaciones con las que podemos complejizar nuestro entendimiento del octubre chileno. Es de esperar que se abra un diálogo fructífero con explicaciones desde diferentes prismas ideológicos para beneficio de la sociedad chilena en su conjunto y para avanzar decididamente en este proceso constituyente que comienza en pocos meses más.

\section{Bibliografía}

Alenda, S., Le Foulon, C. y Suárez-Cao, J. (2020). Evolución de las sensibilidades políticas: hacia una nueva centro-derecha en Chile (87-118). En Alenda, S. (ed.), Anatomía de la derecha chilena: Estado, mercado y valores en tiempos de cambio. Santiago: Fondo de Cultura Económica. EP 